\title{
Audience Opinions on Egyptian Television Advertising and Attitudes towards Product Placement
}

\author{
Tara Al-Kadi \\ Department of Journalism and Mass Communication, the American University in Cairo, Egypt \\ tara_al_kadi@aucegypt.edu
}

Received date: 08 May 2018; Accepted date: 08 June 2018; Published date: 03 July 2018

Academic Editor: Omneya Mokhtar Yacout

Copyright @ 2018. Tara Al-Kadi . Distributed under Creative Commons CC-BY 4.0

\begin{abstract}
This paper explores the perceptions, attitudes and experiences of Egyptian audiences towards television advertising and subliminal advertising they are exposed to through product placement. Six focus groups were conducted in June 2014, encompassing different demographic groups from the Egyptian society. The discussions revealed high levels of criticism of Egyptian advertising. Interestingly, while there was an overall negative stigma associated with the Egyptian broadcast system, including the quantity and ethicality of advertising, the use of product placement, however, found a high acceptance amongst participants.
\end{abstract}

Keywords: Egyptian audiences, television and advertising

\section{Introduction and Background}

Product placement is a marketing technique, where a product, service or a trademark, is included or referred to in works such as television programmes or films for advertising purposes in return for money. OFCOM Code defines it specifically as:
"The inclusion in a programme of, or of a reference to, a product, service or trademark where the inclusion is for a commercial purpose, and is in return for the making of any payment, or the giving of other valuable consideration, to any relevant provider or any person connected with a relevant provider, and is not prop

Cite this Article as: Tara Al-Kadi (2018), "Audience Opinions on Egyptian Television Advertising and Attitudes towards Product Placement ", Journal of Marketing Research and Case Studies, Vol. 2018 (2018), Article ID 940661, DOI: 10.5171/2018.940661 
placement" (OFCOM Code, July 2015, Section 9, p. 47).

Product placement has been practiced for over a 100 years (Newell, 2006). The first clear use of it was in the adventure novel Around the World in Eighty Days (1873), which had references of transport and shipping companies, publicizing them. However, it is not obvious whether the author, Jules Verne, had received any monetary return for including those companies in his novel (Butcher, 1995).

The technique has recently become widespread in Egyptian films and television programmes. The 2001 film Ill Sellem wil Te3ban (Snakes and Ladders), directed by Tarek el Erian, was notorious for product placements of the KFC fast food chain, Marlboro cigarettes, and Heineken beer. Additionally, famous Egyptian film stars Ahmed Helmy, Ahmed el Sakka and Ahmed Ezz have been commonly using product placement for cars like Jeep and Chevrolet as well as smart phones and cafes in their films.

But while product placement promises economic benefits for filmmakers and marketers, currently there are no broadcast policies that address or attempt to regulate this practice.

Recently the Egyptian government has been taking serious and concrete measures regarding the regulation of television, which proves a real interest in reform. A draft media regulation 'Unified Media Law' in late 2015 has addressed various valid problems in Egyptian broadcasting and advertising. However, the law does not address product placement.

And though there is a rise in product placement in both Egyptian cinema and television, this study notes that the lack of sufficient and reliable Arab media research makes it difficult to provide statistics and accurate figures to demonstrate the growth of this trend.
In 2012, global product placement growth was expected to accelerate at a rate of 11.7 per cent to reach $\$ 8.25$ billion. The growth was mainly due to a significant rise in product placement on TV in most countries as well as increases in product placement in content produced for digital platforms and in music (Quinn, 2012, p. 10). In fact, television is the primary medium which brands use for product placement, rising at a rate of 10.9 per cent in 2011 to reach $\$ 4.76$ billion, representing a 64.4 per cent share of the paid placement market (Quinn, 2012, p. 10).

\section{Statement of the Problem}

With changes in sentiments and behaviours in post-revolutionary Egypt, it became important to explore whether Egyptian audiences have altered attitudes and feelings towards specific marketing concepts, namely product placement for this research. It is very timely given the fact that this practice has been growing rapidly in television and cinema.

After the revolution, the country has witnessed a youth rebellion on the traditional and ethical concerns rose as to what has been and what has become acceptable. This paper presents results from focus groups, giving an original insight into Egyptian viewer perceptions of product placement and its ethicality. A study of Egyptian attitudes about product placement for beer, for example, or other religiously banned products yields valuable results for both advertisers and media policymakers. Further, this research is unique and significant because it investigates the sentiments of Egyptians about product placement, given the conservative Muslim background of the majority.

This audience research replicates certain components of previous international studies that explore viewer feelings about product placement. Qualitative focus group technique is used to give an in depth of view of feelings and thoughts of audiences. 


\section{Literature Review}

\section{Product Placement and Realism}

Product placement is often accused of disengaging audiences' immersion in the viewing experience. Critics of product placement claim it defies realism by creating an exaggeration of reality through pushing products to the foreground of scenes. It is true that using generic products is not very realistic, because in the real world there are brands; yet, at the same time, it is hard to equate reality to a continuous set of advertisements.

When not overly used, product placement tends to appear to be an extension of a realistic setting, allowing brand messages to be communicated subconsciously (Wenner, 2004; Nelson \& McLeod, 2005). Similarly, Nelson and Devanathan (2006) have conducted audience research studies and concluded that product placement increased audience perceptions of film realism and aided in character development.

Nevertheless, Wenner (2004), primarily interested in the ethicality of product placement, claims that it might actually threaten a plot's sense of realism. Wenner (2004) raises a very logical critique; he wonders how product placement is considered realistic when brands are rarely depicted in a negative manner. For example, the car manufacturer sponsoring a film will reject a car crash scene in which its product is negatively portrayed. This study has attempted to investigate whether Egyptian audiences consider product placements realistic or whether they find them damaging to the viewing experience.

\section{Product Placement and Commercialism}

Many scholars believe that the exaggerated use of product placement taints media content with commercialism, regardless of whether it enhances realism or not. Hackley, Tiwsakul, and Preuss (2008), Sung et al. (2008), Gutnik et al. (2007), Schejter (2004), and Wenner (2004) express concern about the ethicality of excessive commercialism as brands infiltrate media. The commercialisation and materialism critique addresses the evolving role of the media in general and goes beyond the realm of product placement and the impact product placement has on the reception of individual programmes.

Various communication scholars have criticised the global trend towards commercialisation of media (Artz, 2007; Hamond, 2004; Herman \& Chomsky, 1988; Klein, 2010; Mullen, 2010; Murdcok \& Golding, 1999). Herman and Chomsky (1988) argue that in liberal democratic systems such as the United States, media have functioned under corporate control as opposed to state control. They establish that media have become alarmingly profit-oriented, with advertising being the main source of income. This study directly probes Egyptian audiences about this theme.

\section{Product Placement's Link to Media Effects Theories}

Existing research in the field focuses on how audiences evaluate product placement and the extent to which they are persuaded by it. This is directly related to a variety of media theories. Some of the main theories linked to product placement are cultivation, 'third person' and social learning.

In the case of the cultivation theory, it is assumed that repeated exposure affects viewers' judgement of the real world. The theory argues that cumulative exposure to particular media messages relates to viewers' perceptions of the prevalence of certain behaviours. Thus, more drinking on screen may translate into viewers considering drinking to be the norm. Russell et al. (2009) note that younger viewers are more vulnerable to television influences because they use television portrayals as a tool to understand adult behaviours they seek to imitate.

The third person effect suggests that people tend to believe that mass media messages have a greater effect on others than on 
themselves. Accordingly, viewers who often dismiss the potential danger of product placement for certain brands to themselves may do so because of this effect. They assume that they are not as naïve and vulnerable as others. Galician (2004); Nelson, and McLeod (2005); Ong (2004); and Shin and Kim (2011) find strong evidence in support of the third person effect in viewer evaluations of product placement.

Following the logic of social learning theory, audiences may identify with, model, and imitate experiences of their favourite actors. Depictions of consumption influence audience reception via the characters, who serve as aspirational figures, role models, and agents of socialization, revealing themselves by means of the products they use, the usage context, and the usage outcomes (Russell \& Stern, 2006, p. 134).

These behaviours become issues of serious concern when those admired actors smoke or drink recklessly (Sung et al., 2008). This study seeks to further examine audience perceptions and attitudes about product placement vis-à-vis the social learning, cultivation and 'third person' media effects' theories.

\section{International Audience Evaluations of Product Placement}

Various international studies have attempted to replicate or build upon the original research conducted by Gupta and Gould (1997), which compares audience attitudes towards product placement of 'neutral' noncontroversial products to those that are considered more 'ethically charged' such as alcohol and tobacco. In a way, Gupta has become a pioneer in the investigation of audience perceptions of the ethicality of product placement.

All audiences examined - American, Chinese, Singaporean, Australian, British, French, and Canadian - were generally disapproving of ethically charged products. Accordingly, it can be asserted that ethically charged products illicit criticism across different nationalities, although the degree of disapproval may vary from one country to another (Brennan et al., 2004; Gould et al., 2000; Mckechnie \& Zhou, 2003). Some cultures are more accepting of product placement of neutral products than others. For example, the Chinese and Singaporeans are less accepting of product placement than people in North America (Karrh et al., 2001; Mckechnie \& Zhou, 2003).

Another fascinating conclusion offered by the studies is that, in terms of gender comparisons among American, Austrian, French, Canadian, Chinese, Australian, and Singaporean research participants, females tended to be more critical of ethically charged product placement as opposed to males, who were more accepting of product placement of alcohol, guns, and tobacco (Gupta et al., 2000; Gould et al, 2000; Karrh et al., 2001; Mckechnie \& Zhou, 2003; Brennan et al., 2004). This study seeks to further explore the Egyptian audiences' perspective, which has been absent from previous international audience studies on product placement.

However, in contrast to the above quantitative studies, the current research offers a more unique qualitative approach. It is influenced by the study of DeLorme and Reid (1999), who relied on first-person audiotaped accounts of eight different focus groups and 30 in-depth interviews, with the aim of understanding how product placement is viewed by film viewers and translated into their daily life activities. This approach has inspired the methodological design of this study.

\section{Research Question}

The general research question this study attempts to answer is:

What are the perceptions, attitudes, and lived experiences of television viewers in Egypt about advertising in general and product placement, more specifically?

\section{Methodology}

A focus group-based audience research was implemented to rectify a main drawback of 
previous product placement audience studies, which were almost all quantitative. In previous studies (Brennan, Rosenberger III, \& Hementera, 2004; Gould et al., 2000; Gupta \& Gould, 1997; Gupta et al., 2000; Karrh, Frith, \& Callison, 2001; Mckechnie \& Zhou, 2003), respondents were simply offered a list of topics related to the main theme and were left to discuss freely their thoughts and feelings. This technique, although useful for quantification and generalisations, does not allow for further elaboration by the participant through openended or 'why' or 'how so' questions. Whilst the present study builds on the audience research related to placement of ethically questionable products, it is uniquely qualitative because it offers a more useful interpretive approach.

Prior to holding focus group discussions, a pilot focus group session was conducted to allow for improvements of the original audience research design. It is relevant to clarify here that reference to 'Egyptian channels' denotes Egyptian terrestrial state channels, such as the Nile channels, as well as privately owned Egyptian satellite channels based in Egypt such as, but not limited to, CBC, Dream TV, Mehwar, and Al Hayat. Given that this was an exploratory qualitative study. The discussions were loosely based on the open-ended questions presented in Table 1 below.

\section{Table 1: Guiding Questions for Focus Group Respondents}

\begin{tabular}{|l|l|}
\hline 1. & How do you feel about Egyptian television advertising? \\
\hline 2. & What sort of regulation, if any, would you like to see applied on TV spot ads? \\
\hline 3. & $\begin{array}{l}\text { How do you feel about product placement? Can you recall any product placement? Which kind } \\
\text { of product placement works for you? Why or why not? Is there anything you dislike about } \\
\text { product placement? }\end{array}$ \\
\hline 4. & $\begin{array}{l}\text { What do you prefer spot advertising or embedded promotional content like product placement? } \\
\text { Why? }\end{array}$ \\
\hline 5. & $\begin{array}{l}\text { What do you think about celebrities or attractive actors and characters using product } \\
\text { placement? }\end{array}$ \\
\hline 6. & Do you feel that product placement needs to be regulated? Why? How so? \\
\hline
\end{tabular}

Six focus group discussions were conducted in June 2014 (as detailed in the next table). The aim was to incorporate different demographic groups from the Egyptian

society, but, taking into account practical and risk factors such as safety, members were all

Cairo-based residents. Below are the details for the audience research participants. 
Table 2: Focus Group Participant Demographics

\begin{tabular}{|l|l|l|l|}
\hline $\begin{array}{l}\text { Focus } \\
\text { Group }\end{array}$ & Age & Gender & Socio-Economic Background \\
\hline 1 & $18-25$ & 4 males/ 4 females & $\begin{array}{l}\text { Moderate to high socio-economic educational } \\
\text { background }\end{array}$ \\
\hline 2 & $35-50$ & 4 males/ 4 females & $\begin{array}{l}\text { Moderate to high socio-economic educational } \\
\text { background }\end{array}$ \\
\hline 3 & $18-25$ & 6 males & Lower socio-economic educational background \\
\hline 4 & $18-25$ & 6 females & Lower socio-economic educational background \\
\hline 5 & $35-50$ & 6 males & Lower socio-economic educational background \\
\hline 6 & $35-50$ & 6 females & Lower socio-economic educational background \\
\hline
\end{tabular}

For ease of reference, the next table (Table 3) contains a simple coding system developed to help identify and refer to the demographic information of focus group participants.

Table 3: Participant Coding Guide

\begin{tabular}{|l|l|l|l|}
\hline $\begin{array}{l}\text { Participant } \\
\text { Reference }\end{array}$ & Gender & $\underline{\text { Age }}$ & Socio-Economic Background \\
\hline FYH & 4 females & $18-25$ & $\begin{array}{l}\text { Moderate to high socio-economic educational } \\
\text { background }\end{array}$ \\
\hline MYH & 4 males & $18-25$ & $\begin{array}{l}\text { Moderate to high socio-economic educational } \\
\text { background }\end{array}$ \\
\hline FOH & 4 females & $35-50$ & $\begin{array}{l}\text { Moderate to high socio-economic educational } \\
\text { background }\end{array}$ \\
\hline MOH & 4 males & $35-50$ & $\begin{array}{l}\text { Moderate to high socio-economic educational } \\
\text { background }\end{array}$ \\
\hline
\end{tabular}




\begin{tabular}{|l|l|l|l|}
\hline MYL & 6 males & $18-25$ & Lower socio-economic educational background \\
\hline FYL & 6 females & $18-25$ & Lower socio-economic educational background \\
\hline MOL & 6 males & $35-50$ & Lower socio-economic educational background \\
\hline FOL & 6 females & $35-50$ & Lower socio-economic educational background \\
\hline
\end{tabular}

Focus group analysis was guided by the grounded theory approach. Numerous themes emerged from focus group conversations. Overall, there was consensus about the main issues. However, there were differences found - especially when relating to age, gender, and socio-economic background. These instances are highlighted and analysed in the following sections. The next table depicts the relevant findings.

\section{Findings}

The research findings indicate that participants had very favourable attitudes towards product placement. This will be explored in more detail in the latter part of this paper. However, with the exception of the product placement technique, participants shared a strong dislike of other forms of advertising. The next section is devoted to analysing/assessing these criticisms.

\section{Criticisms of Television Advertising}

Focus group participants expressed four main criticisms in relation to advertising, as portrayed in Figure 1:

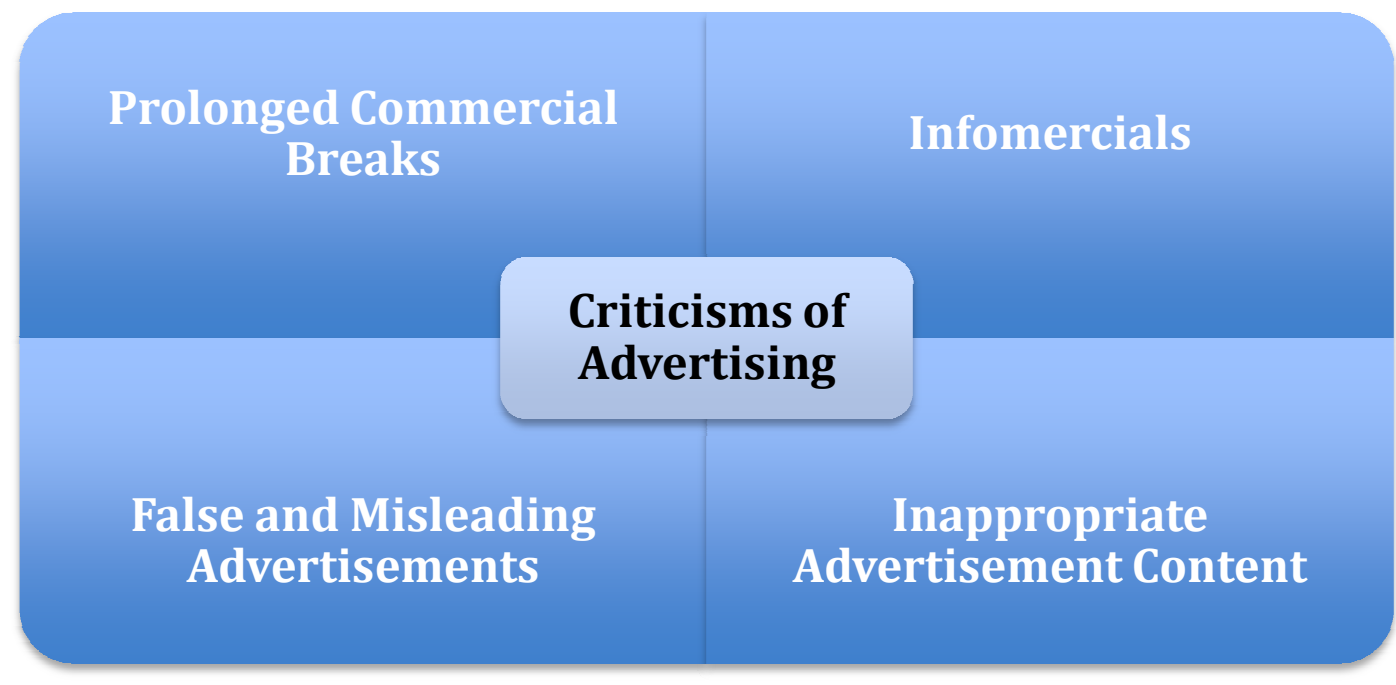

Figure 1: Main Advertising Criticisms 


\section{Prolonged Commercial Breaks}

Excessively prolonged commercial segments were the strongest and most commonly cited reason why participants had negative perceptions about advertising. To demonstrate how frustrating the lengthy advertisement breaks were, focus group participants listed several examples.

"A local channel called Star Cinema sometimes has 45minute commercial breaks. A film for example can sometimes start at $1 \mathrm{pm}$ and finish at $6 \mathrm{pm}, "$ complained an $\mathrm{FOH}$.

Participants thought there was no clear system guiding the scheduling of advertising breaks. In their view, the latter were haphazard and unregulated. It should be pointed out that the draft Unified Media Law has addressed this issue and called for the regulation of commercial breaks. However, this is yet to be applied on Egyptian channels.

One significant and repeated complaint made by focus group participants regarding advertisements was that such segments interrupted the viewing experience to such an extent that viewers felt disengaged from what they were watching. As early as 40 years ago, Williams (1974) elaborated on the concept of 'flow' in relation to US commercial television viewing, which he stated was becoming increasingly disruptive of the viewing.

Policymakers who have an obligation to consider the viewer perspective should not ignore the notion that advertisements were increasingly disengaging audiences and becoming a source of irritation to them. For example, an FOL said:

"The worst things are TV ads that may disconnect us from what we are watching. Sometimes you forget what you were watching or the scene you stopped at. This is very frustrating."

On the other hand, several females in different groups said they coped with this annoying phenomenon by proactively making use of redundantly extensive advertisement breaks to get up and do chores or watch another programme in parallel. Thus, beyond the method of using new technologies to skip advertising or switch channels, Egyptian female viewers were using the commercial breaks for practical purposes. This corresponds to the findings of Tierean and Roman (2015, p. 76) who note that whilst only 4.3 per cent of audiences watch television ads, 35.8 per cent (of which a majority are females) do something else whilst advertisements are running and 59.8 per cent switch channels.

\section{Frustration with Infomercials}

Closely related to the participant frustration with prolonged commercial breaks was criticism of infomercials, which have become frequent on some new Egyptian satellite channels. Infomercials, known in Europe as teleshopping, began in the United States. Typically, infomercials include a website or phone number where viewers can immediately and directly make a purchase. Some are long running, from 15 to 30 minutes, whilst others are shorter, ranging from 30 to 120 seconds (Martin, Bhimy, \& Agee, 2002; Wayne \& Rosser, 2004). This is also true for Egyptian television infomercials.

Six out of the 40 participants complained that infomercials always seemed to "drag on" without a defined endpoint. They were clearly put off by the infomercials they were seeing on some general interest channels on Egyptian TV. Participants from lower socioeconomic focus groups mainly voiced this critique. In comparison, the upper socioeconomic participants did not refer to infomercials at all. One reason may be that 
this social class had different viewing preferences and did not watch the same satellite channels.

The growth of infomercials directly links to the issue of excessive commercialisation of global media addressed in the literature review.

Poor audience research, particularly in nonurban areas, makes it difficult to find reliable information on viewing preferences. Here, it must be emphasised that concrete and substantive audience research is scarce and sometimes unreliable in Egypt (Ali, 2012) and the Arab World, more generally (Amin, 2008).

\section{Advertising as False Information}

Truth in advertising was another issue highlighted by focus group participants. Many believed that a large number of commercials were giving false, deceptive, or misleading information. They listed examples of advertisements, which trick audiences into calling in and paying telephone fees without knowing upfront how much they would be charged. An MYL explained,

"There are ads for hotlines you call to appear on game shows. They do not mention the price of the call and the games shows are often non-existent."

\section{Another FYL complained,}

"There are channels like Tok Tok and Taxi Cinema where a single movie could last five hours because of the deceptive ads trying to sell us stuff that are very bad quality. For example, there is a character called 'Dr. Hassassen'. He always mentions ways of curing diseases. He is just a talkative conman."

Remarkably, a particular category of products prompted a lengthy discussion: weight control and diet drugs. Participants were very concerned about the safety of such advertised solutions and questioned the ethicality of such advertising. Advertising weight loss products has been a growing trend on Egyptian television screens and has raised suspicions because the weight loss drugs or herbal concoctions being promoted offer vague manufacturing, licensing, and safety information. They also make unrealistic promises, but this may not be obvious to individuals who are desperate for a weight loss fix.

Participants in the 18-25-year-old upper socio-economic group were eager to see regulation in this area. It also was notable that, compared with older participants, the younger ones seemed more aware of the presence of false or misleading advertising on television. Whilst they believed they were immune to manipulative or misleading commercials, they said they were very concerned about Egyptians who were less educated and from lower socio-economic classes. This links to the 'third person' effect discussed in the literature review.

\section{Inappropriate Ads}

Without being prompted, participants viewed many advertisements as unsuitable. Several commercials were immediately mentioned by participants as examples of vulgar and sexual insinuations in current television advertisements. Amongst them were advertisements for sexual enhancement drugs, which, according to all groups, were promoted in a very explicit manner. Participants also noted that even some advertisements for regular products, such as food, heavily relied on sexual appeals or vulgar humour.

Mothers were very concerned about any type of sexual openness. An FOH mother gave the example of advertisements for female sanitation towels, which were too indiscrete.

$$
\begin{aligned}
& \text { "How can they show those } \\
& \text { ads? Children watch and } \\
& \text { ask questions!" }
\end{aligned}
$$

Interestingly the solution the participants of the focus groups offered was extreme: banning these advertisements. They did not suggest a middle ground, where, for example, 
such advertisements would be aired, but during later hours - an approach taken in some countries. The wish for an outright ban seems to be directly related to the culture, because Egyptian children generally do not have set bedtimes and families usually do not restrict television-viewing hours.

\section{Embracing Product Placement}

The focus group participants expressed high acceptance of product placement in comparison to traditional forms of advertising. The strong reception of product placement was not anticipated, given that previous international audience studies have revealed that in more conservative cultures audiences are less accepting of product placement. This becomes clearer in the next section.

\section{Product Placement Is Preferred To Spot Advertising}

The focus group discussions revealed a strong preference for product placement as a promotional tactic when compared to traditional spot advertising. Participants favoured product placement because it is perceived to be subtle and imbedded. They liked that it did not disengage them from the viewing experience.

What was remarkable was how familiar participants were with product placement, especially the younger, 18-25-year olds. They listed a large number of examples. The latter also indicates that the use of product placement in Egyptian films and television has been growing since the younger participant demographic was comparatively more informed about contemporary companies, brands, and their product paraphernalia compared to the elder demographic, who were largely not as aware about product placements. A reason for this may be that younger viewers have been growing up in a culture where product placement is the norm, whilst the current commercialism and brand consciousness were not as excessive at the time the older participants were growing up. In fact, from the focus groups, it was evident that younger viewers were very knowledgeable about brands in general.

An MOL went on to explain the many benefits and possible disadvantages of product placement listing many factors, which made it effective, such as free, repeated promotion through reruns of programmes and films. He also noted the risks associated with it, such as the fact that some subtle placements could also mean that brands may go unnoticed by viewers. His familiarity with product placement and its benefits was interesting, especially since he was a shopkeeper who had no formal marketing or advertising background.

An FYL also referred to its effectiveness as a promotional tool by adding,

"It [product placement] is definitely better than ads. If the actor, for example, eats a chocolate bar, I find myself wanting to know what the brand is so I can buy it."

Whilst an MYL made the valid remark that when it came to providing technical information, advertising was sometimes more persuasive than product placement, the overwhelming majority generally preferred product placement, because it conveniently resolved the problem of disrupted viewing caused by spot advertising.

Other participants in different focus groups also pointed out some advantages of product placement as an effective promotional tool. An FYL, for example, referred to a particular film in which the lead actor wore shirts of a certain brand. She exclaimed that the social impact was "incredible", as all males in her neighbourhood started to wear them. This was met by agreement amongst others in her focus group who began to list instances of films where leading male and female actors started cultural trends through placed brands in clothing, mobile phones, and cars.

The above observations are significant for three reasons. First, it is interesting that audiences were not only familiar with 
product placement, but they also seemed to be aware of its potential impact on culture. Second, the findings highlight the audience connection to and the influence of onscreen actors. This seems to support the theories of cultivation and social learning addressed in the literature review. Third, not only was product placement seen as an effective promotional tool, but it was also a preferred one. One MOH explained:

"It [product placement] is good. It doesn't cut me off the film." Another FOL added,

“They [placements] don't waste time, because the movie is not cut." Those sentiments indicate that many people will be satisfied with product placement if it remains subtle and does not interrupt viewing.

An MOL said,

"That would be very boring, as if I am going to watch an ad not a movie." Generally, it was a well-liked promotional tactic, which they unanimously agreed was also very realistic. However, over time, if product placement became more dominant, then the viewers might be less accepting of it. Hence, there is a need now to think about a policy that can maintain that level of acceptance and not cross the boundaries of public taste.

As discussed in the literature review, a major concern of product placement critics was that it makes films and programmes seem less realistic as brands are placed in an exaggerated manner on the screen. According to the focus group discussions, covering the brand names or blurring them was "unrealistic and ridiculous." An FYL said,

"I am really annoyed when they sometimes hide the logo on water bottles. It looks so unreal."

The logic is that in a world where brands stand out, television only reflects this reality.

Given the wide acceptance of product placement in all focus groups, it is not surprising that the majority of participants did not favour any changes or the implementation of broadcast regulation in this area. Overall, participants believed that regulation of product placement was unnecessary. Unlike spot advertising, which was perceived as intrusive, product placement was not viewed as an area, which needed the particular attention of policymakers or television censors.

When the moderator introduced examples of how some countries used a ' $P$ ' logo to alert viewers to the use of placement on television, participants in all focus groups did not think that such measures were necessary or desirable.

\section{Product Placement and Ethically Charged Products}

With respect to regulation of ethically charged products, several points are relevant. Most important to note, participants did not raise concerns about ethically charged brands, such as alcohol or cigarettes. They began to elaborate on the use of controversial brands in film or programming only after prompting. When directly asked about placements in this category, one or two members in each group preferred limiting the frequency of placements of ethically charged brands to avoid exaggeration. It was clear from participant tone and level of engagement that this topic was not a major area of concern. The majority agreed that audiences were already familiar with brands in this category and that viewing them on screen would not make a big difference in terms of creating added interest in the product or motivating people to buy it. 
A second remarkable finding was that participants did not treat ethically charged products such as alcohol and cigarettes as one category. The understanding of the Egyptian research participants about what constituted "ethically charged" differed from previous studies on this topic, pioneered by Gupta and Gould (1997) and later replicated by other scholars with American, Chinese, Singaporean, Australian, British, French, and Canadian audiences. It seems that religion was a main factor, which participants relied on in determining what was ethical and what was not. For example, an MOL suggested that an aphrodisiac placement was more acceptable than a placement of alcohol. Additionally, tobacco placements were deemed more acceptable than alcohol placements, which drew some criticism, albeit limited. This was expected, as the Egyptian culture is influenced by religion (mainly Islam), which prohibits the consumption of alcohol.

Another observation related to ethically charged products was that participant opinions about placement of ethically charged brands were consistent across gender, age, religion, and socio-economic level. For example, the veiled females were not less accepting of ethically questionable product placement than the other participants, nor were older participants more against it. This varies from results produced by other international studies on audience attitudes towards placement of controversial products. In these earlier audience studies, females and older participants were slightly less accepting of ethically charged brands. Here, there was no evidence for a 'third person' effect in this part of the discussion and the reason for this was not clear. Although participants were aware of product placement's marketing purposes, they were not concerned about being tempted to buy products whilst watching a programme.

\section{Discussion}

The topic of product placement has been directly linked and compared to advertising on Egyptian television. Focus group participants expressed severe frustration with the duration of commercial breaks and the frequency of infomercials on television. They stressed their discontent, stating their need for change in the current system, noting that advertising segments needed to be considerably shorter and have clearly defined scheduled slots.

Participants also emphasised the need for censorship in relation to inappropriate sexual or vulgar content in Egyptian ads. Lastly, but of equal importance, focus groups expressed a strong desire for new regulations which reflected consumer rights principles.

On the contrary, when they compared traditional advertising to product placement, it was clear the concept was welcome.

The focus group discussions indicated that whilst there was an overall negative stigma associated with Egyptian advertising including the quantity, quality, and ethicality of spot advertising - the use of product placement on Egyptian television was highly accepted by participants. Those who were eager to see changes applied to television programmes, films, and advertisements did not have similar opinions about product placement. In fact, there was a general agreement that current product placement practices were favourable and did not require change or intervention through regulation.

\section{Conclusion}

Although the focus groups discussions revealed little interest in product placement regulation at this stage, results revealed the worries viewers had about the broadcast system within which product placement is currently developing. The focus groups were particularly vocal in their criticism of the current television advertising with respect to prolonged unregulated commercial breaks, false misleading and inappropriate ad content, and excessive infomercials. The discussions highlighted the concerns and 
values of the participants, which should be taken into consideration in any future regulation pertaining to product placement. Results also underscored the need to help the public become more aware of the possible (unseen) long-term implications of product placement.

Whilst the overall dissatisfaction with Egyptian television advertising was anticipated, the findings directly related to product placement were not. What was unexpected was the degree of acceptance of product placement for ethically charged products. Participant demands for regulation and censorship of advertising based on ethical grounds were not extended to product placement. Reasons for this discrepancy were directly related to how participants felt about spot advertisements. Product placement has become the better option, for now, with its relatively subtle and disengaging nature. However, if its use increases and expands, there may be more concerns, particularly with placements of ethically charged products such as alcohol.

Throughout the focus group discussions, all participants underscored the need for a more accountable television system. They wanted commercials to be limited and advertisers to be held accountable. What seems to be essential is for viewers to develop a clearer picture of product placement, one in which their judgement is not tainted by their

\section{References}

1. Ali, S. (2012). Statistical data collection project on film and audiovisual markets in 9 Mediterranean countries: 1. Egypt. Euromed Audiovisual III. Retrieved from http://euromedaudiovisuel.net/Files/2013/ 08/20/1377006300957.pdf

2. Amin, H. (2008). Arab media audience research: Developments and constraints. In K. Hafez (Ed.), Arab media: power and weakness (pp. 69-90). New York, NY: Continuum.

3. Artz, L. (2007). The corporate model from national to transnational. In L. Artz \& Y. R. Kamalipour (Eds.), The media globe: trends repulsion to advertisement. It is also likely that as product placement grows and becomes more frequently used, viewers will feel differently about the need to regulate it. For example, if Egyptian viewers were to become fully aware of product placement's cultivation effects, they may call for regulation. It would be hard to believe that parents would continue to accept product placement for cigarettes and alcohol.

Media education may not be as evolved in Egypt as it is in other countries. Any future product placement policy should consider the demand for more accountability in the domain of television advertising. A future policy should no doubt calculate the financial benefits product placement offers television producers. However, it should do so without compromising the audience call for improved content quality and credibility.

\section{Recommendations}

It is recommended that marketers and advertisers must be cautious about permitting placement of particular products. Given that the Egyptian culture is religious and relatively conservative, it is preferable to ban placements in particular brand categories such as alcohol, tobacco, and other culturally or religiously controversial products.

in international mass media (pp. 141-162). Lanham, MD: Rowman \& Littlefield.

4. Barkawi, B. (February 14, 2011). Why don't Arabic movies feature product placement? Retrieved from http://marketinghub.bayt.com/articles/why -don\%E2\%80\%99t-arabic-movies-featureproduct-placements

5. Brennan, S., Rosenberger III, P., \& Hementera, V. (2004). Product placements in movies: an Australian consumer perspective on their ethicality and acceptability. Marketing Bulletin, 15, 1-16.

6. DeLorme, D., \& Reid, L. (1999). Moviegoers' experiences and interpretations of brands in films revisited. Journal of Advertising, 28(2), 71-95. 
7. Galician, M. L. (2004). A leading cultural critic argues against product placement: An Interview with Mark Crispin Miller. Journal of Promotion Management, 10(1/2), 219-222.

8. Gould, S. J., Gupta, P. B., \& GarbnerKrauter, S. (2000). Product placement in movies: a cross-cultural analysis of Austrian, French and American consumers' attitudes towards this emerging, international promotional medium. Journal of Advertising, 29(4), 41-58.

9. Gupta, P. B., Balasubramanian, S., \& Klassen, M. (2000). Viewers' evaluations of product placements in movies: Public policy issues and managerial implications. Journal of Current Issues \& Research in Advertising, 22(2), 41-52.

10. Gupta, P. B., \& Gould, S. J. (1997). Consumers' perception of ethics and acceptability of product placements in movies: Product category and individual differences. Journal of Current Issues and Research in Advertising, 19(1), 37-50.

11. Gutnik, L., Huang, T., Lin, J. B., \& Schmidt, T. (2007). New trends in product placement. Strategic Computing and Communications Technology, 1-22. Retrieved from http://people.ischool.berkeley.edu/ hal/Co urses/StratTech09/Tech/Preso/D-

placement.doc

12. Hackley, C. (2008). Branded entertainment: Product placement and brand strategy in the entertainment business. International Journal of Advertising, 27(5), 924-925.

13. Hammond, A. (2004). Pop culture Arab world! Media, arts, and lifestyle. doi:9781851094547, 1851094547

14. Herman, E., \& Chomsky, N. (1988). Manufacturing consent: The political economy of the mass media. New York, NY: Pantheon. 15. Hermann, E. \& McChesney, R. (1997). The global media: The new missionaries of corporate capitalism. London, UK: Cassell. 16. Jernigan, D. H., Ostroff, J., \& Ross, C. (2005). Alcohol advertising and youth: A measured approach. Journal of Public Health Policy, 26(3), 312-327.

17. Karrh, J. A., Frith, K. T., \& Callison, C. (2001). Audience attitudes towards brand (product) placement: Singapore and the
United States. International Journal of Advertising, 20(1), 3-24.

18. Martin, B., Bhimy, C., \& Agee, T. (2002). Infomercials and advertising effectiveness: An empirical study. Journal of Consumer Marketing 19(6), 468-480.

19. Mckechnie, S. A., \& Zhou, J. (2003). Product placement in movies: a comparison of Chinese and American consumers' attitudes. International Journal of Advertising, 22(3), 349-374.

20. Mullen, A. (2010). Twenty years on: The second-order predication of the HermanChomsky propaganda model. Media, Culture \& Society, 32(4), 673-690.

21. Murdock, G., \& Golding, P. (1999). Common markets: Corporate ambitions and communication trends in the UK and Europe. The Journal of Media Economics, 12(2), 117132.

22. Nelson, M. R., \& Devanathan, N. (2006). Brand placements Bollywood style. Journal of Consumer Behaviour, 5(3), 211-221.

23. Nelson, M. R., \& McLeod, L. E. (2005). Adolescent brand consciousness and product placements: Awareness, liking and perceived effects on self and others. International Journal of Consumer Studies, 29(6), 515-528.

24. Newell, J., Salmon, C. T., \& Chang, S. (2006). The hidden history of product placement. Journal of Broadcasting \& Electronic Media, 50(4), 575-594.

25. OFCOM Broadcasting Code. (2015, July 1). Incorporating the Cross-Promotion Code. Retrieved from http://stakeholders.ofcom.org.uk/binaries/b roadcast/code-july-

15/Ofcom_Broadcast_Code_July_2015.pdf

26. Ong, B. S. (2004). A Comparison of product placements in movies and television programs: An Online research study. Journal of Promotion Management, 10(1/2), 147-158. 27. Quinn, P. (2012). Global product placement forecast 2012-2016: Executive summary. $P Q$ Media. Retrieved from http://www.pqmedia.com/globalproductpla cementforecast-2012.html\#displayMore 28. Russell, C. A., Russell, D. W., \& Grube, J. W. (2009). Nature and impact of alcohol messages in a youth-oriented television series. Journal of Advertising, 38(3), 97-111. 
29. Russell, C. A., \& Stern, B. (2006). Consumption in soap operas from Brazil, New Zealand, and the U.S.: Production, products, and process. Advances in Consumer Research, 33(1), 134-135.

30. Schejter, A. (2004). Product placement as an international practice: Moral, legal, regulatory and trade implications. Paper presented at the 32nd Research Conference on Communication, Information and Internet Policy, Arlington, Arlington.

31. Shin, D. H., \& Kim, J. K. (2011). Alcohol product placements and the third-person effect. Television\& New Media. 12(5), 411440.

32. Sung, Y., Choi, J., \& De Gregorio, F. (2008). Brand placements in Korean films, 19952003: A Content analysis. Journal of International Consumer Marketing, 20(3/4), 39-53.

33. Tierean, O.M., and Roman, D.E. (2015). Commercial breaks vs. product placement: what works for young consumers? Bulletin of the Transilvania University of Brașov Series
V: Economic Sciences, 8(57), 71-78.

34. Tiwsakul, R., \& Hackley, C. (2006). Young

Thai and UK consumers' experiences of television product placement-engagement, resistance and objectification. Paper presented at the Advances in Consumer Research - Asia-Pacific Conference Proceedings.

35. Wayne, R., \& Rosser, J. (2004). What is an infomercial? Advertising \& Society Review, $5(2)$.

36. Wenner, L. (2004). On the ethics of product placement in the mass media entertainment. In M.-L. Galician (Ed.), Handbook of product placement in the mass media (pp. 101-132). New York: Best Business Book.

37. William Butcher (translation and introduction). Around the World in Eighty Days, Oxford Worlds Classics, 1995, Introduction. 38. Williams, $\mathrm{R}$. Television:Technology and cultural form. London, UK: Routledge. 